\title{
Diferenças e vozes em Ana Hatherly e Salette Tavares: Para uma nova estética
}

\section{Catherine Dumas \\ Université Sorbonne-Nouvelle Paris 3}

\begin{abstract}
Resumo: Duas artistas portuguesas, Ana Hatherly e Salette Tavares, são expoentes de maior importância da vanguarda experimental dos anos 60, PoEx. Inscrevem-se no âmbito modernista do artista total ao praticar as artes plásticas, a literatura, em especial a poesia, e o ensaio teórico. A sua obra propõe, cada uma consoante as suas modalidades, a construção de uma nova estética com, no seu âmago, um sujeito em devir afirmativamente feminino, subversivo e criador de linguagens. 0 seu compromisso com uma nova definição do Artista desemboca na visão de um mundo no qual a liberdade de criação se aplica à vida. Ana Hatherly, pelos seus auto-retratos desmultiplicados em vertigem barroca, e Salette Tavares, com os seus textos performativos e os seus objetos-mundo, inauguram uma contemporaneidade que levará o experimentalismo para além das suas fronteiras cronológicas.
\end{abstract}

Palavras-chave: Ana Hatherly, Salette Tavares, experimentalismo, sujeito feminino, criação-mundo

Résumé: Deux artistes portugaises, Ana Hatherly et Salette Tavares, président à l'avant-garde expérimentale portugaise des années 60, PoEx. Elles s'inscrivent dans le cadre moderniste de l'artiste total, pratiquant les arts plastiques, la littérature, dont tout spécialement la poésie, et l'essai théorique. Leur œuvre propose, selon les modalités propres à chacune d'elles, la construction d'une nouvelle esthétique avec, en son centre, un sujet en devenir assurément féminin, subversif et créateur de langages. Leur engagement dans une nouvelle définition de l'Artiste débouche sur la vision d'un monde où la liberté de création s'applique à la vie. Ana Hatherly, à travers ses autoportraits démultipliés dans un vertige baroque, et Salette Tavares, avec ses textes performatifs et ses objets-monde, inaugurent une contemporanéité qui portera l'expérimentalisme au-delà de 
ses frontières chronologiques.

Mots-clé: Ana Hatherly, Salette Tavares, expérimentalisme, sujet féminin, création-monde

Ana Hatherly e Salette Tavares são dois expoentes, duas mulheres do experimentalismo português. As únicas. Mas quando pensamos que o Modernismo, o primeiro, mas também o segundo, não integrou nenhuma artista feminina (lembremo-nos das dificuldades de uma Irene Lisboa para, no seu tempo e não só, sair de uma marginalidade forçada), cabe-nos valorizar o facto de que tanto Ana Hatherly quanto Salette Tavares encontraram na aventura experimentalista um espaço de liberdade reivindicada, espaço próprio para a afirmação de uma voz feminina e a reinvenção do sujeito, cada uma à sua maneira.

Reinventar o sujeito é, para Ana Hatherly, antes de tudo, reinventar uma linguagem. O seu experimentalismo, sabemo-lo, faz dela uma artista poliédrica, nas suas vertentes da literatura (criação poética, ficcional, crítica, teórica, editorial), das artes visuais (pintura, desenho, poema visual, tag acrílico, miniatura), do cinema e do happening. Cinema e happening juntam-se, aliás, no filme Rotura realizado a partir da performance que a artista fez na galeria Quadrum em 1977 e que encena exemplarmente a atitude experimentalista. Direi então que a nova linguagem inventada por Ana Hatherly é a da intermedialidade, em constante movimento entre as diversas artes, fazendo-as corresponder-se, sobretudo no que toca à poesia e às artes visuais. E isso alicerçado num saber construído pela pesquisa científica da professora universitária, especialista da arte barroca. A produção ensaística de Ana Hatherly mostra bem isso, nem que seja, entre outros ensaios, através de: A Casa das Musas: uma releitura crítica da tradição (Lisboa: Editorial Estampa, 1995), O Ladrão Cristalino: aspectos do imaginário baroco (Lisboa: Edições Cosmos, 1997, Prémio de Ensaio da Sociedade Portuguesa de Autores, 1998), Poesia Incurável: aspectos da sensibilidade barroca (Lisboa: Editorial Estampa, 2003).

A releitura que faz Ana Hatherly da tradição barroca, e não só, incide em toda a sua 
criação poética. Nisto, a poeta actua à boa maneira do modernismo brasileiro antropófago. O produto devolvido após a digestão das influências (Harold Bloom), da tradição é, para usar um termo francês apropriado, décapante. A reinvenção de uma linguagem aplica-se, entre outras invenções, à declinação do nome Ana, desmultiplicando-o, metamorfoseando-o, como nesta "Variação XV" de "Leonorama” (Hatherly 1980: 238):

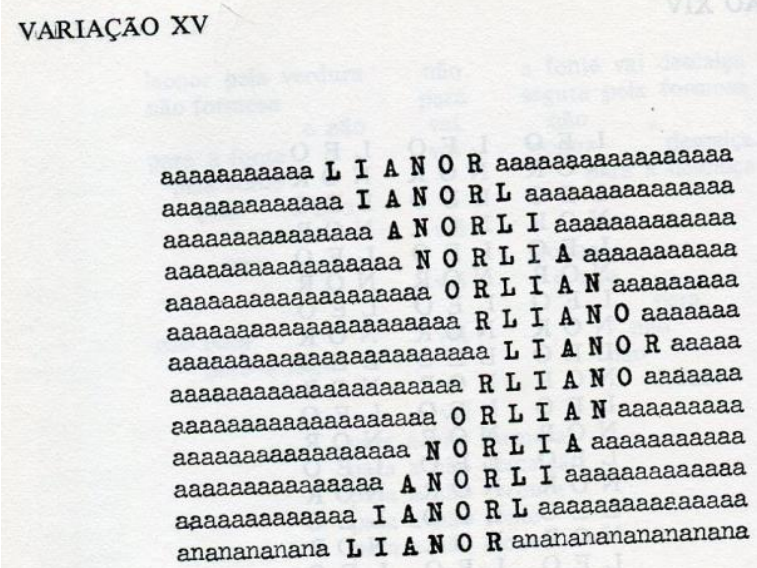

0 " $n$ " é recuperado do clássico Lianor para afirmar, na última linha, a presença do nome da artista que, assim, despersonalizando-se através das numerosas mediações da sua identidade nominal, acaba por se expor sem ornamentos, nua. Esta possibilidade de se reinventar a si mesma como sujeito feminino, como artista, surge da nova linguagem do objecto poético verbivocovisual que é acionada por este poema.

Em Litoteana do volume Eros Frenético (Hatherly 1968), aparece a personagem de 
Dona Ana, substituto de D. Juan no feminino, desmultiplicada até ao infinito. A partir daí, falarei numa arte do auto-retrato em Ana Hatherly, em que o sujeito auto-retratado é um sujeito performativo. Ana Hatherly, tal como Salette Tavares como veremos mais adiante, inventa uma nova subjectividade. 0 auto-retrato em Ana Hatherly passa sempre por mediações, seja de figuras tutelares, seja da ironia desconstrutora, que reconstroem um sujeito outro. A artista inventa-se duplos, como Dona Ana, mas também Rosalina, o porco que atravessa as Tisanas com uma boa dose de autoderisão. A título de exemplo, comentarei alguns auto-retratos tirados da obra pictural (Hatherly 2005). Os dois primeiros datam da época em que a artista se mudou de Londres para Lisboa, no começo dos anos 70. 0 primeiro é directamente inspirado de Matisse, "à la façon de", como é legendado. ${ }^{1}$

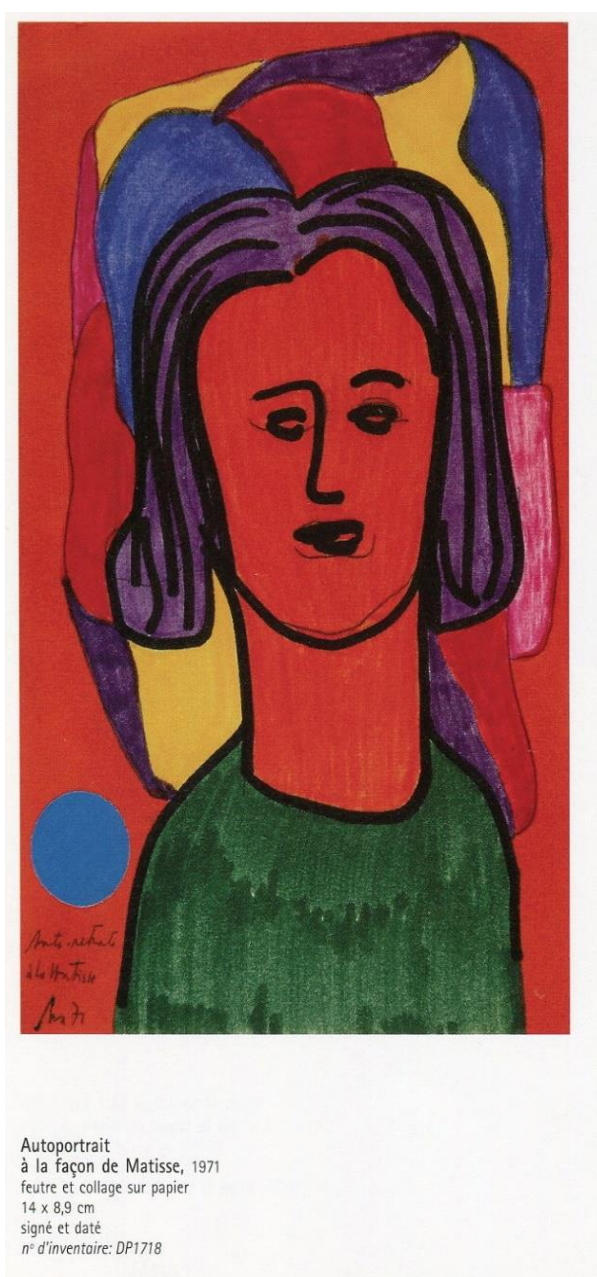


No segundo, o retrato acha-se num medalhão central rodeado por um marco em forma de mosaico associando ícones em relação com a obra escrita das Tisanas. A legenda, mais uma vez, é explícita: “(...) - dans le cadre le contraste entre Mondrian et le monde mythico-magique des 'Tisanas' -". As formas relacionam-se com Mondrian pela sua geometria e pelas cores. As linhas de escrita reproduzem um excerto de Tisanas, obra em prosa feita de fragmentos filosófico-poéticos, livro que se deu a conhecer por várias edições aumentadas ao longo da obra de Ana Hatherly, como se se tratasse de um diário. 0 desenho do tronco com os círculos concêntricos até ao cerne, assim como as extremidades das madeixas de uma cabeleira vinda de fora do quadro remetem ao exercício ontológico (autoanálise como sujeito feminino e sujeito criador) levado a cabo em Tisanas.

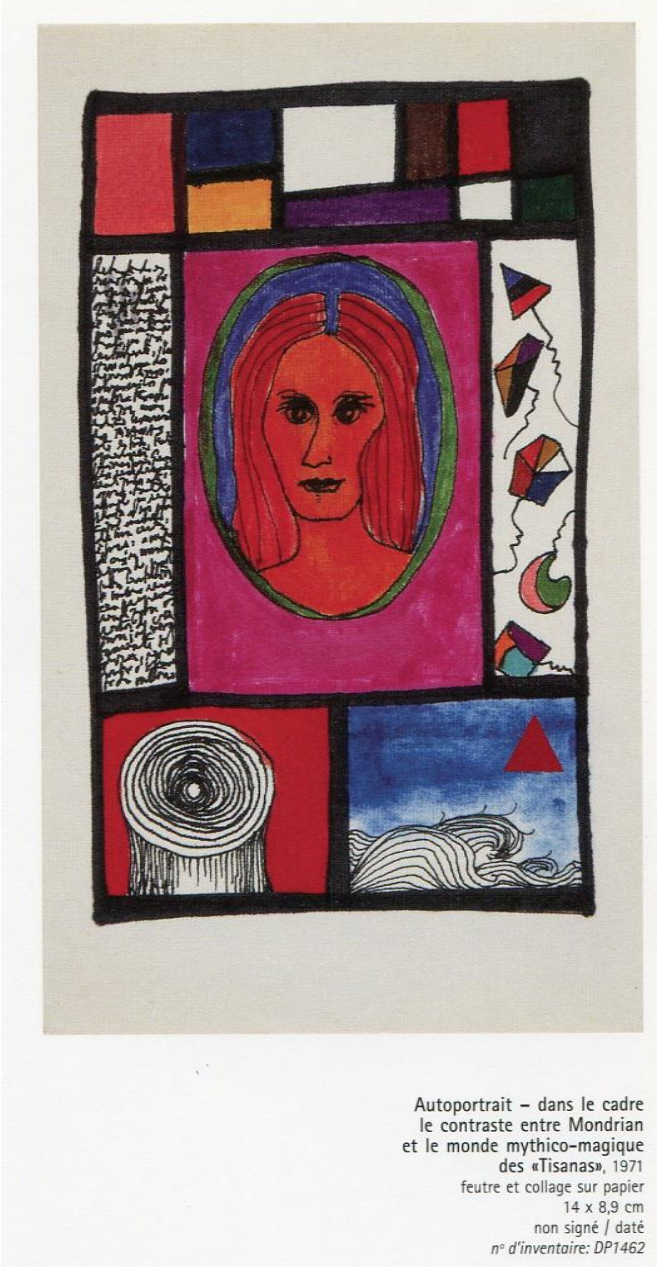


No caso destes dois auto-retratos, a mediação de Matisse e de Mondrian remete-nos à tradição modernista nas suas versões do fauvismo e do neoplasticismo. Há uma série de três auto-retratos intitulados Autoreto à Füssli (1973) (Hatherly 2005) que podem funcionar ora como paródia ora como pastiche do quadro do Romântico negro Füssli, Pesadelo:

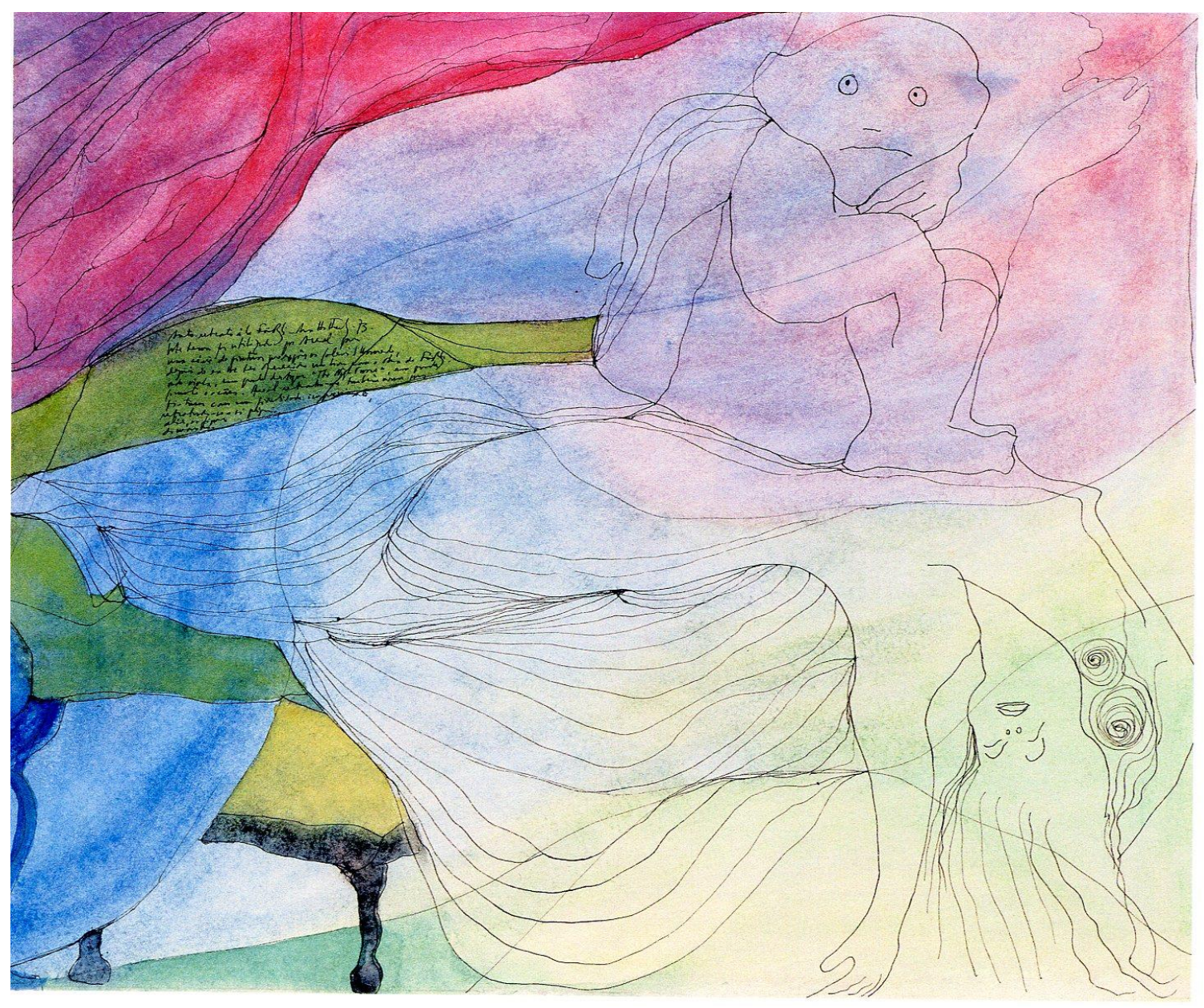




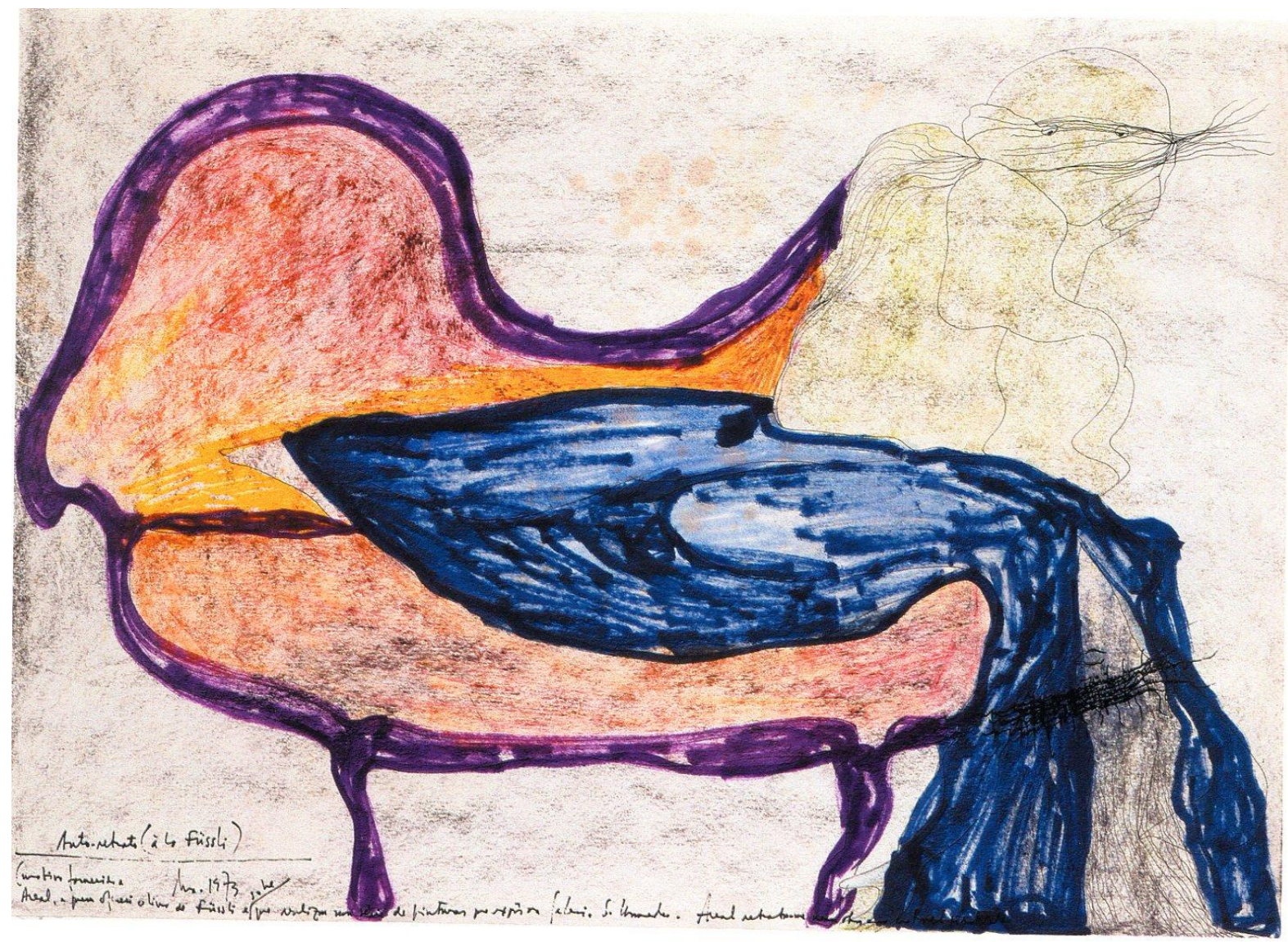

As versões de Ana Hatherly retomam de Füssli a posição dos corpos. Mas a artista portuguesa faz destes corpos puros fantasmas, ao negar-lhes quer a cor, quer os traços da cara. Na primeira versão, avistam-se as linhas de escrita no respaldo da poltrona, no segundo plano. Na segunda versão, as linhas de escrita nascem dos corpos, essencialmente o da mulher decotada. Este processo é ainda mais nítido na terceira versão onde a escrita fica no primeiro plano até cobrir o motivo pictural. Penso então nos desenhos de escrita de Mapas da Imaginação e da Memória (1973) e pergunto se não poderão, também eles, ser interpretados como auto-retratos.

Citarei mais exemplos de auto-retratos em Ana Hatherly, como a tríade de A Idade da Escrita (1998), intitulada "Auto-retrato. Parafraseando Sor Juana Inês de la Cruz e Sóror Madalena da Glória" e que, apelando à mediação dos poemas conventuais da idade barroca, acaba com este soneto: 


\section{Auto-retrato}

Este que vês, de cores desprovido,

o meu retrato sem cores é

e de falsos temores já despido

em sua luz oculta põe a fé.

Do oculto sentido dolorido,

este que vês, lúcido espelho é

e do passado o grito reduzido,

o estrago oculto pela mão da fé.

Oculto nele e nele convertido

do tempo ido excusa o cruel trato,

que o tempo em tudo apaga o sentido;

E do meu sonho transformado em acto,

do engano do mundo já despido,

este que vês, é o meu retrato. (Hatherly 1998: 26)

0 primeiro verso é uma glosa de cada um dos hipotextos. Encontramos em Sor Juana Inés de la Cruz "Este que ves, engaño colorido", e em Soror Madalena da Glória "Este que vês de sombra colorido". De glosa em glosa, de "paráfrase" em "paráfrase", o auto-retrato faz-se mais sombrio, mais escuro, e vela-se. A indicação da ausência de cores é iterativa, tal como o é a ocultação operada pela fé (ocultação da luz, dor, noção de destino trágico). 0 soneto, forma nobre por excelência, desenha a filiação elegíaca de uma voz feminina da qual, em filigrana, Florbela, "Soror saudade", não estará ausente.

Falarei agora daquilo que Judith Butler chama de "inversão irónica", em Sujeitos do desejo (Butler 2011). A partir da novela O Mestre (1963), elabora-se um sujeito feminino definido como sujeito desejante, e que desafia a lei paterna em ficções ao mesmo tempo grandiosas e derisórias, que são experimentações do mito de si mesma. Vimos a este propósito a figura de Dona Ana. A personagem da Discípula de $O$ Mestre é outra. Encarna o 
desamor e a solidão de que padece este sujeito feminino performativo, numa perseguição amorosa desmultiplicada que apela à tapeçaria da Dame à la Licorne, à lenda lorquiana de Don Perlimplin y Belisa, à Sonata a Kreutzer, à Lição de Anatomia de Rembrandt, etc. Tais variações podem desaguar em cenas caricaturais como a "Meditação sobre o problema sexual". No seu livro de poesia mais recente, A Neo-Penélope, Ana Hatherly pratica a derisão até à voluptuosidade. Encena várias personagens femininas como "Alice no país dos anões", "As antigas damas japonesas", a própria Néopenélope, ou Clio desdobrada no carro da poeta em “Carta de amor em metáfora de automóvel” (Hatherly 2007).

Salette Tavares impôs-se como uma artista performativa de primeira importância. Lembro-me, por exemplo, da personagem da Sou Toura Petra que a artista utilizou para fazer happenings na ArCo, onde aliás leccionava. ${ }^{2}$ Tive o privilégio de ver no seu espólio uns continhos inéditos da Sou Toura Petra.

A primeira fotografia infra foi tirada durante uma destas performances.

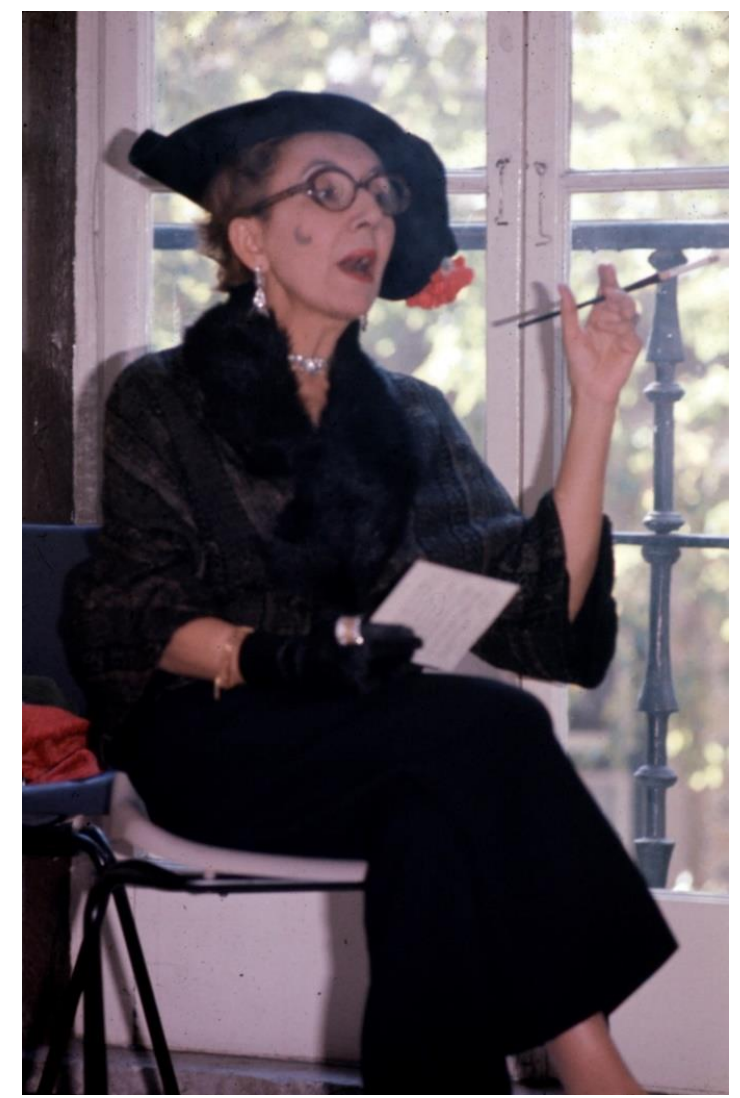


No espólio de Salette, cuidadosamente guardado pela filha, Salette Brandão, figuram, ao lado dos contos da Sou Toura Petra, vários livros de ficção e de ensaio por publicar, se bem que se pode falar no conjunto como de uma obra inacabada, é dizer inacabada de publicar na sua totalidade. Destaco do espólio as seguintes narrativas: o romance dramático Outro outro (1963); Irrar, narrativa experimental cujo manuscrito foi instalado na exposição Brincar em 1979 e que é um jogo criativo irónico-humorístico com a ortografia portuguesa; Baile Mecânico, guião para uma fita experimental datado de Setembro de 1962; O Kâgado, guião para uma fita experimental datado da Primavera de 1966. Existem também dois livros de ensaios prontos para serem publicados: Sintra no Jardim da Esmeralda, que trata dos jardins românticos de Sintra e investiga as poéticas do Romantismo aplicadas às teorias da paisagem; A Dialéctica das Formas cujas provas em chumbo foram derretidas e cujas páginas dactilografadas foram o objecto de uma instalação auto-irónica, também na exposição Brincar, em 1979. As três últimas destas fotografias foram tiradas na exposição Brincar.
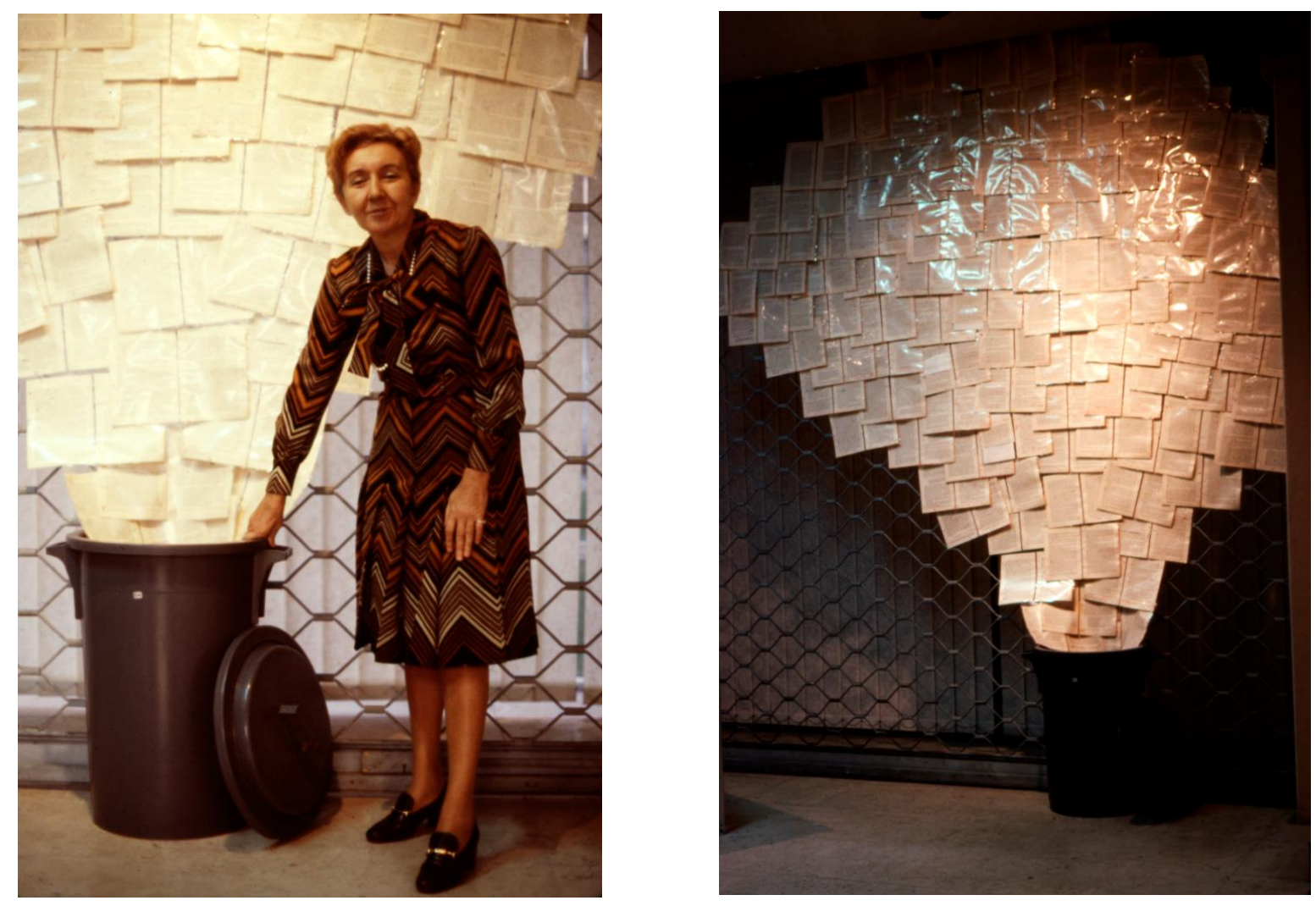


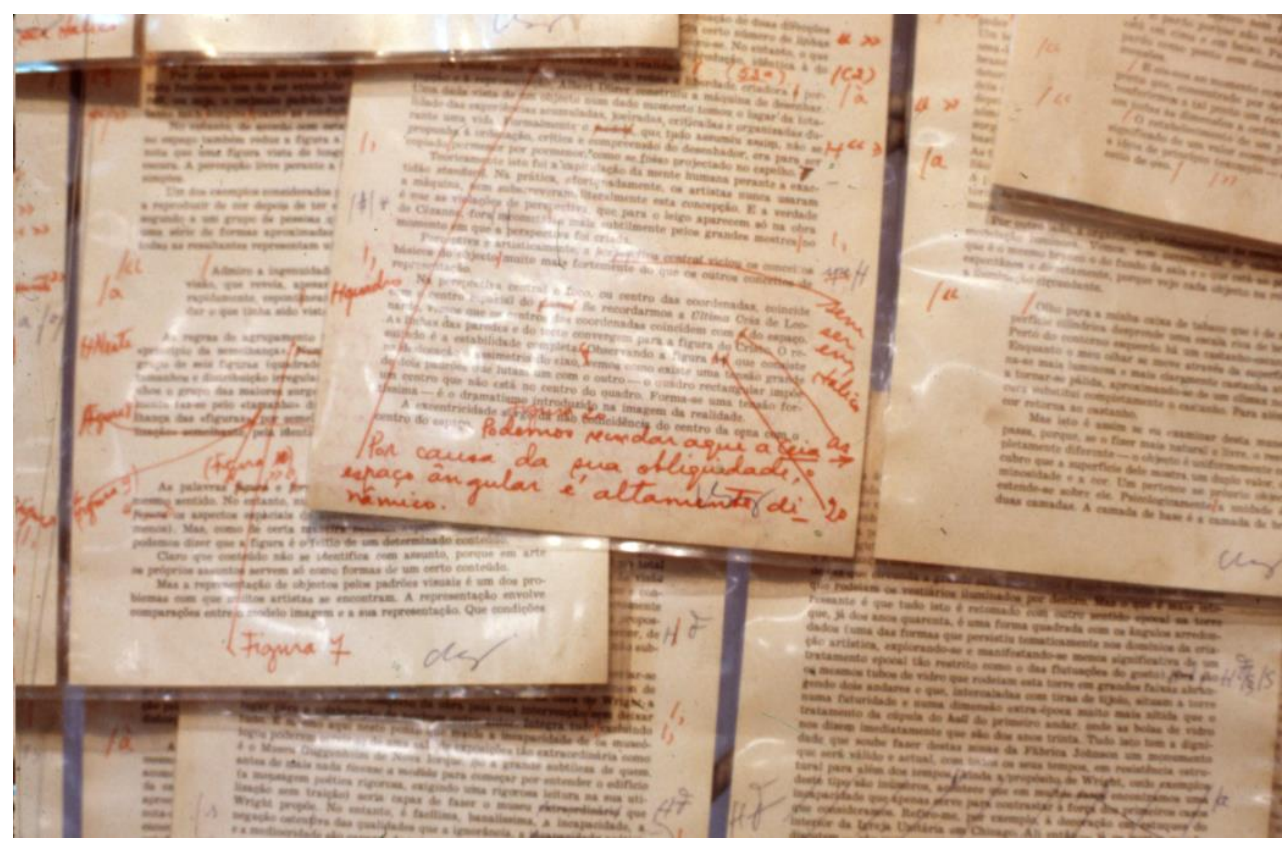

Vemos aqui que a artista encena, com uma autoderisão cáustica, a própria arqueologia e a história da sua obra, relacionando entranhadamente a parte ensaística com a parte criativa. O happening serve para isso também. Os dois primeiros capítulos dos onze capítulos de Dialéctica das Formas correspondem a artigos saídos na Brotéria. Já escrevi sobre os escritos teóricos de Salette Tavares, em especial a propósito da estética da "forma aberta" (Dumas 2016). Quero agora mostrar como a autora encena, através do texto performativo, as teorias que desenvolve de outra forma em capítulos de livros mais "sérios". Pegarei num texto encontrado no seu espólio, sem data nem indicação de que tenha sido publicado: ${ }^{3}$ 


\section{Catherine Dumas}

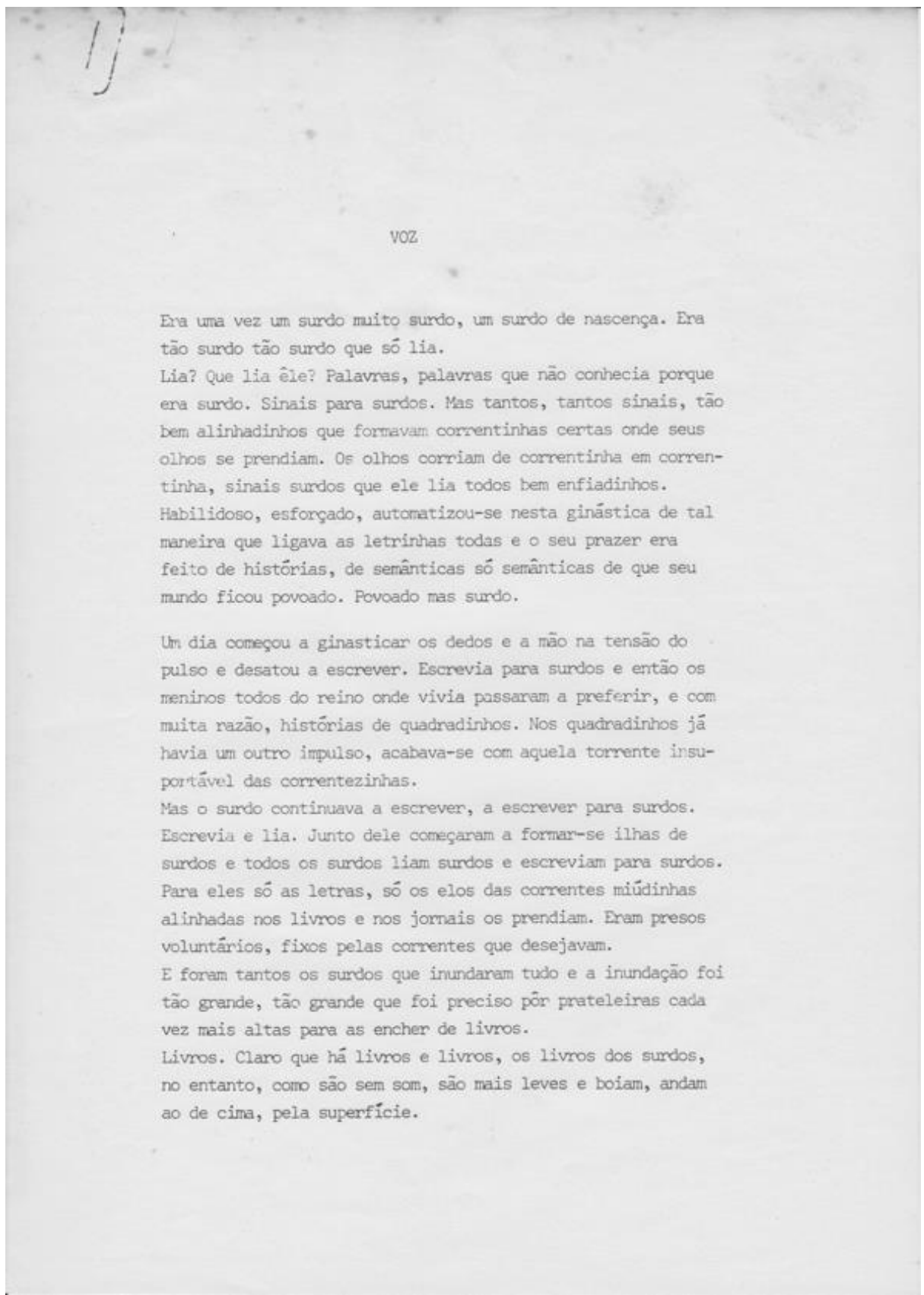


Eles julgan que as palauras säo letrus coladas, arranjadas em conposiçōes certas, em frases que se decifrum con dicionários. Os dicionärios são livmos e entre livmos e livros tudo se passa para os surdos. De resto eles gostan de uma forma fácil de comunicar, a gmanitica dos livnos e nada de entrechos difíceis, que isso de gramática já $\hat{e}$ muito, tratamentos de linguagen e outras quejandas complicaçōes sāo actos que podem prejudicar aquele simplissimo encadear de letras míủinhas e é preciso não haver interferências difíceis pana cérebros sem ouvidos. Sem sentidos, dizemos melhor, pois eles, desgraçados, vítinas de uma tāo grande calanidade da natureza que os privou da música, até iggonam que as letras possan ser sinais de sons: para eles só ex-siste aquela correria de elos entrenhados miúdanente päginas a fio. Ser escritor é produzir isso mesno. Ser leitor $\vec{e}$ seguir com a vista essa informaçāo das letrinhas. Por isso, una data de surdos juntarminse e coneçanam a ser produtones de mais letrinhas, letrinha letrinhas que seguiam chatas e insuportãveis para os não pacientes. Estes, os não pacientes, refugiavan-se nas entrelinhas. Mas os surdos, certos, rectos, melhores e mais eficazes na grande velocidade da conduçâo das suas pupilas, vencian todas as corridas e ficaram cegos porque só vian letrinhas.

Un dia estes surdos descobrinam que havia livros en que as correntes de letrinhas se quetravam, que tinham letras ao conträrio, que as histốrias jâ não eram aquelas histórias faceiszinhas com príncipio meio e fin, que nâo havia adjectivos nem palavrinhas letrinhas muito correntinhas. Deixanam crescer o dedo indicador e apontaram. Depois meteran o dedo enorme num frasco de tinta e fizenam un cartaz acusador: elitistas.

0 dedo ena enorme, estava todo sujo mas eles decidinam nāo chupar no dedo. Tinhan sido senpre maiores, maiones na letra miüdinha e ao que aquele dedo os obrigana: O1hando o dedo pensanam: antes a facilidade do que a felicidade. 


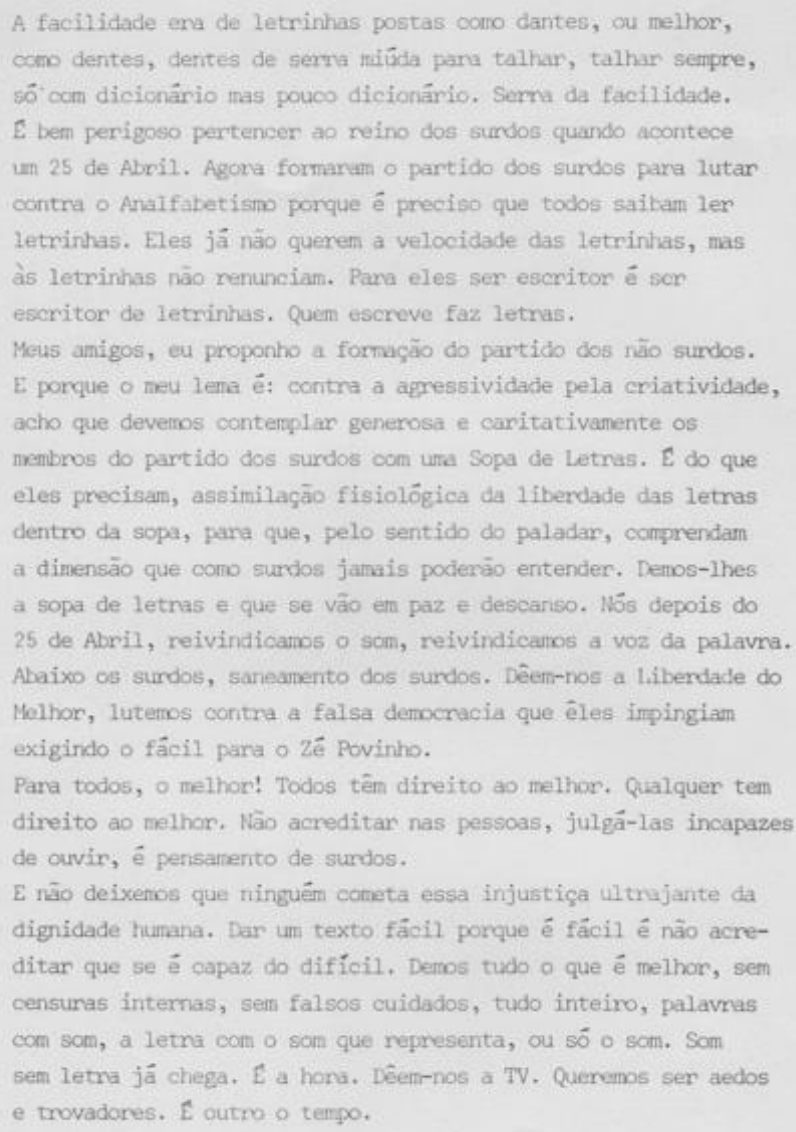

Este texto, tal como as fotografias dos happenings e da instalação, testemunha da performatividade do texto, conceito a partir do qual Salette recusa para o sujeito do artista qualquer hiato com o sujeito empírico. A ironia lúdica que une um e outro tem um teor altamente político, tal como em Ana Hatherly. O sujeito de Salette exerce, tal como o sujeito de Ana Hatherly, uma total liberdade criativa e vital. O texto "Voz" funciona, na sua segunda 
parte, em forma de panfleto. A primeira parte, a fábula do surdo leitor de textos escritos só para surdos, descreve uma ditadura à Orwell. Percebemos que "Voz" foi escrito a seguir ao 25 de Abril de 1974, pelas propostas alusivamente irónicas da criação de "um partido de não surdos" por um colectivo, "nós", que reivindica "a voz da palavra". Um lema sobre a liberdade corre ao longo da última página: "Dêem-nos a liberdade do melhor". Trata-se da liberdade de criação para os experimentalistas que praticam o texto "verbivocovisual", da liberdade de leitura com cada um dos cinco sentidos para qualquer leitor, e do direito de usufruir a "liberdade do melhor" contra uma falsa democracia anti-elitista. Ao encenar-se como mulher e artista, Salette Tavares propõe portanto um modelo social: "É outro tempo".

A estética de Salette Tavares considera um todo que é o mundo. A transfiguração que actua, de acordo com Arthur Danto, nos objectos banais, projecta-se para o próprio "eu autor", enfatizado pela artista portuguesa. Por isso mesmo, ela propõe na sua obra multifacetada "uma Estética nova que se insere no estudo da comunicação dialogante do homem com o mundo" (Tavares 1965: 5). A sua criação estende-se ao espaço sagrado configurado pelos objectos simples que fabrica, espaço de religação entre os seres, e entre os seres e o quotidiano: "A faca oferecida pelos filhos para..." (Tavares 2014: 87).

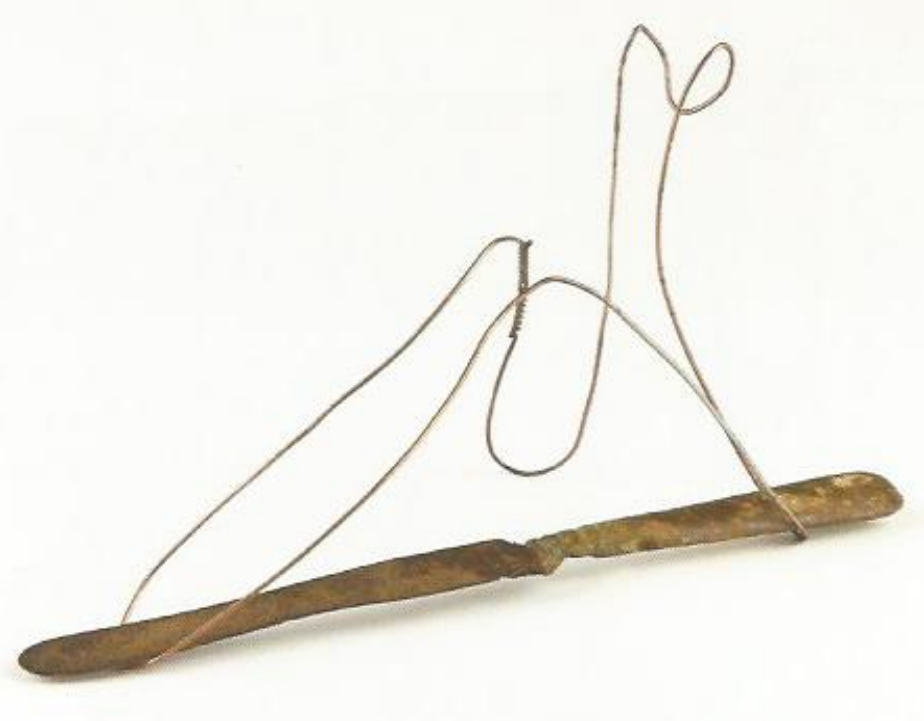


A ideia de purificação necessária para uma criação contaminada pelo merchandizing do objecto fica bem patente em muitos dos objectos da exposição "Poesia Espacial" (2014), sobretudo aqueles feitos a partir da recolha do lixo do mar nas praias de Portugal, como Tábua verde com conchas (Tavares 2014: 71).

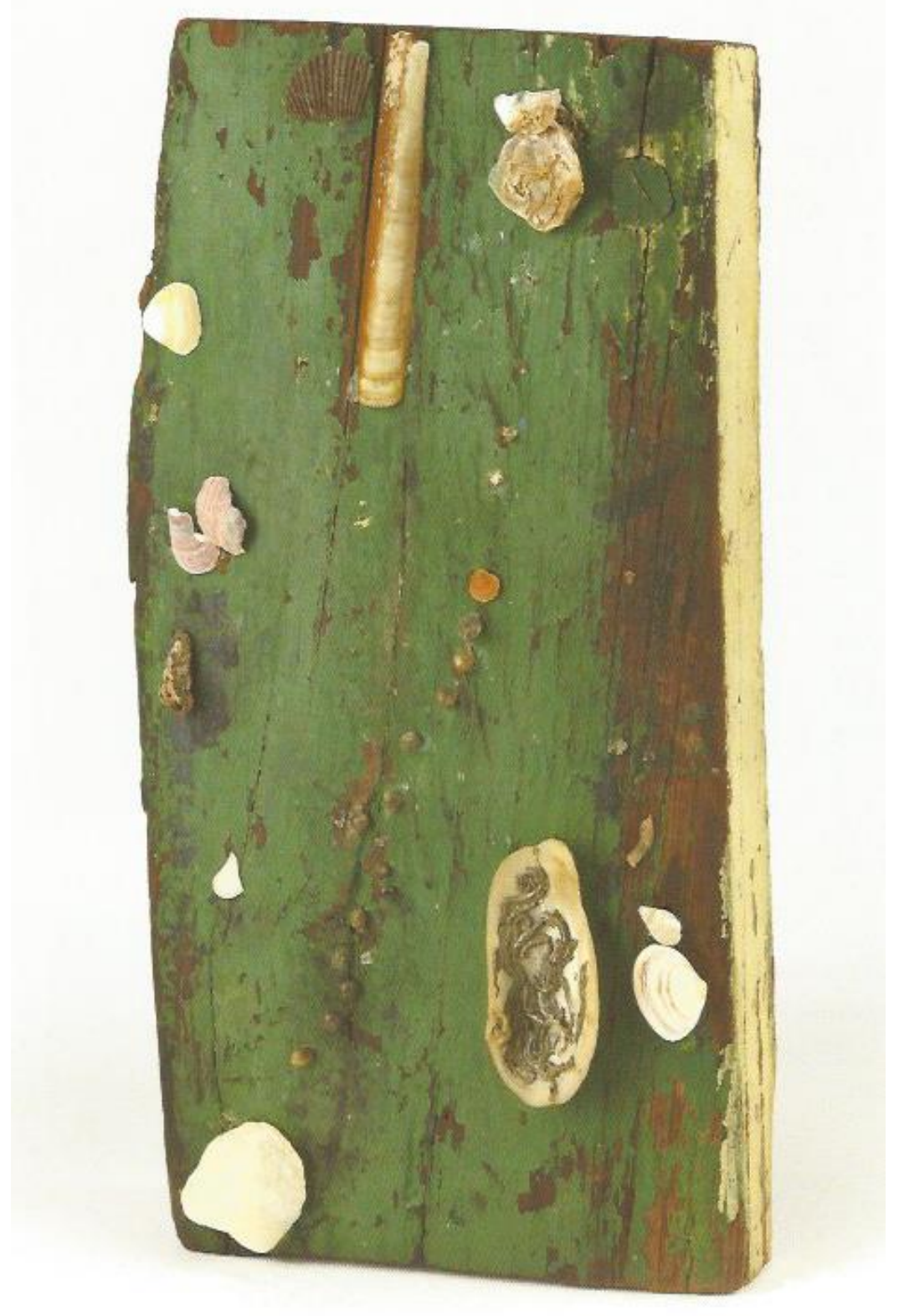


Trata-se de uma colagem de conchas numa tábua que, pintada a verde com a cor das algas, parece recém-apanhada na praia. As conchas são coladas numa disposição supostamente aleatória, tal como se fossem depositadas pela maré. Esta composição pode ser vista como uma obra tanto naturalista, como "religiosa" (vide Arthur Danto), sugerindo uma sinestesia em que o olfacto e o ouvido reconstituem, para além da vista, um mundo de sensações, o do meio marítimo. Esta estética da apanha lembra os respigadores da cineasta que antecipou a Nouvelle Vague, Agnès Varda, tanto no seu filme Les plages d'Agnès (2000) como em Les glaneurs et la glaneuse (2008). Estes filmes, posteriores à criação de Salette Tavares, comungam no mesmo credo, o carácter sagrado dos objectos do real, especialmente aqueles do espaço comummente categorizado como feminino, do lar e do quotidiano. Salette erige toda uma mitologia à volta deste espaço, ao abri-lo à dimensão de mundo.

O conjunto da obra poética, da obra visual e dos ensaios sobre a criação de Salette Tavares formula propostas para aquilo a que chama "uma Estética nova". Transfigurando o mundo objectal e o sujeito artista que o recebe, esta obra abre a criação ao mundo, o da origem, mas também o de um futuro entrevisto no qual a criação artística é desejada como uma coordenada vibrante da vida. A artista resume bem o seu compromisso com a humanidade nas seguintes palavras: "A verdadeira forma artística é consistência, resistência, persistência e a sua vida como continuidade histórica é realmente efectiva", escreve a autora num artigo publicado em 1989 na revista CL, intitulado "Algumas questões de crítica da arte e de estética na sua relação" (Tavares 1989: 45).

Encontro exactamente neste cruzamento da poética experimental com a esfera do privado a experiência concreta do objecto tal como a trabalhou Salette Tavares, juntando a prática de várias artes para configurar os seus objectos "verbivocovisuais" e o seu sujeito artista específicos. É nesta confluência que as duas artistas contempladas se encontram. 


\section{Notas}

\footnotetext{
${ }^{1}$ As fotografias das obras de Ana Hatherly e Salette Tavares são da autoria de Paulo Costa e foram cedidas pelo arquivo fotográfico do Museu Calouste Gulbenkian/Coleção Moderna.

${ }^{2}$ As fotografias dos happenings de Salette Tavares são provenientes do seu arquivo pessoal e foram cedidas pela sua filha, Salette Brandão.

3 O texto "Voz" de Salette Tavares é proveniente do seu arquivo pessoal e foi cedido pela sua filha, Salette Tavares.
}

\section{Bibliografia}

Butler, Judith (2006), Trouble dans le genre, Traduit de l'anglais (Etats-Unis) par Cynthia Kraus, Paris, Éd. La Découverte.

Danto, Arthur (1981), The Transfiguration of the Commonplace. A Philosophy of Art, Harvard University Press.

Dumas, Catherine (2016), “A aventura da 'forma aberta' em Salette Tavares", Revista Colóquio Letras, n.. 193, Lisboa, Fundação Calouste Gulbenkian, Setembro-Dezembro 2016, 39-50.

Hatherly, Ana (1980), Poesia 1958-1978, Coleção Círculo de Poesia, Lisboa, Moraes Editores. -- (1980), "Leonorama", Poesia 1958-1978, Coleção Círculo de Poesia, Lisboa, Moraes editores.

-- (1995), O Mestre, Lisboa, Quimera.

-- (1998), A Idade da Escrita, Lisboa, Edições Tema. 
-- (2005), Centre Culturel Calouste Gulbenkian, Ana Hatherly dessins, collages et papiers peints, Paris, Fundação Calouste Gulbenkian, "Entretien avec Ana Hatherly", propos recueillis par Ana Vasconcelos e Melo.

-- (2007), A Neo-Penélope, Lisboa, \&etc.

Tavares, Salette (1965), Forma e Criação, Lisboa, Edições Brotéria, separata da revista.

-- (2014), Poesia Espacial/Spatial Poetry, Lisboa, Centro de Arte Moderna Gulbenkian.

-- (1989), “Algumas questões de crítica de arte e de estética na sua relação”, Lisboa,

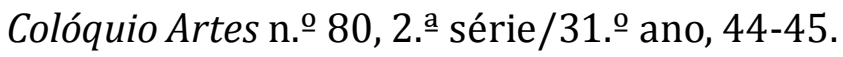

Catherine Dumas é Professora Emérita de Língua e Literatura Portuguesas na Universidade Sorbonne-Nouvelle Paris 3. É autora da primeira tese de doutorado em França sobre a obra da romancista portuguesa Agustina Bessa-Luís e de um livro sobre a mesma autora, Estética e Personagens (Campo das Letras, 2001). Interessa-se em especial pelo cruzamento das escritas do íntimo e do discurso poético, pelas questões de género e pelo diálogo entre os textos literários e a filosofia no âmbito da literatura-mundo. Publicou numerosos artigos sobre a ficção contemporânea e a poesia portuguesas e brasileiras. Traduziu do português para o francês poesia, ficção, teatro e diários. É membro externo do ILCML e colabora, entre outras, na revista Colóquio Letras. 